\title{
GESTÃO DOS ATIVOS DE ESTRUTURAS METÁLICAS E DE DISTRIBUIÇÃO DE FLUÍDOS GASOSOS NA ARCELORMITTAL TUBARÃO*
}

Cinara Piazzarolo Lana Madeira ${ }^{1}$ Julio Cesar Maciel Rezende ${ }^{2}$ Marcelo Marchesi Martinelli ${ }^{3}$ Laudelino Fonseca Junior ${ }^{4}$

\section{Resumo}

Foi desenvolvida uma metodologia de análise, classificação quanto a condição de conservação e priorização das atividades de inspeção, conservação e manutenção das estruturas metálicas e redes de distribuição de fluídos gasosos na ArcelorMittal Tubarão a fim de realizar a correta gestão destes ativos, com foco na minimização dos riscos e redução dos custos no longo prazo, além de contribuir para tomada de decisão estratégica nos orçamentos plurianuais. A Metodologia desenvolvida envolve uma análise em função da condição atual dos seus ativos, da degradação destes ao longo do tempo e dos recursos empregados ao longo dos anos para recuperação estrutural ou pintura preventiva, sendo a base fundamental para a geração de um ciclo de manutenção preventiva com visão centralizada, especializada e sistêmica.

Palavras-chave: Estruturas Metálicas; Degradação; Manutenção Preventiva; Redução de Riscos;.

\section{ASSET MANAGEMENT OF METALLIC STRUCTURES AND PIPES FOR THE DISTRIBUTION OF GASEOUS FLUIDS AT ARCELORMITTAL TUBARÃO \\ Abstract}

A methodology was developed in ArcelorMittal Tubarão in order to analyzing, classifying as regards the condition of conservation and prioritizing the activities of inspection and maintenance of the metallic structures and pipes for the distribution of gaseous fluids in order to carry out the correct management of these assets, with a focus on minimization risks and reduction costs in the long term, as well as contributing to strategic decision-making in multi-annual budgets. The developed methodology involves an analysis based on the current condition of its assets, the degradation of these assets over time and the resources used over the years for structural recovery or preventive painting, which is the fundamental basis to establish a cycle of preventive maintenance with centralized, specialized and systemic vision.

Keywords: Metallic Structures; Degradation; Preventive Maintenance; Risks Reduction;.

1 Engenheira de Manutenção e Integridade Estrutural na área de Gestão de Ativos Centralizados da ArcelorMittal Tubarão na Serra - ES- Brasil.

2 Engenheiro Mecânico na área de Engenharia de Manutenção na ArcelorMittal Tubarão na Serra ES- Brasil.

3 Engenheiro de Confiabilidade na área de Produção de Energia na ArcelorMittal Tubarão na Serra - ES- Brasil.

4 Engenheiro de Confiabilidade na área de Tecnologia e Confiabilidade de Manutenção na ArcelorMittal Tubarão na Serra - ES- Brasil. 


\section{INTRODUÇÃO}

A ArcelorMittal Tubarão é uma unidade de produção integrada de aços planos, localizada em região litorânea do Sudeste do Brasil, com capacidade de produção anual de 7,5 milhões de toneladas de aço em placas e bobinas. Foi fundada em 1983 e opera desde então ininterruptamente.

Pelas informações que caracterizam a companhia acima, é possível observar a relevância do tema Gestão de Ativos de Estruturas Metálicas e Tubulações no seu negócio. Neste contexto, integram-se os fatores produção industrial e seus vários agentes agressivos, localização da planta e sua proximidade com o ambiente marinho, idade das estruturas de suportação e gestão da manutenção.

O processo de produção da siderúrgica Tubarão inicia-se no recebimento e manuseios de matérias primas para produção do Coque e Sinter, que são combustível e carga metálica para os Altos Fornos, onde é produzido o Ferro Gusa. Esta área é denominada área do Gusa e tem processo de características industriais próprias e com alto grau de corrosividade para as estruturas metálicas. O ferro gusa segue então para Aciaria onde é produzido e refinado o aço carbono, seguindo no processo para a área de produção de Placas e Bobinas. Estas áreas, denominadas áreas do Aço, embora possuam grau de corrosividade alto para as estruturas metálicas, têm características menos agressivas à degradação do aço carbono do que a área do Gusa. A Figura (I) mostra resumidamente o processo esquemático de produção de aço na ArcelorMittal Tubarão.

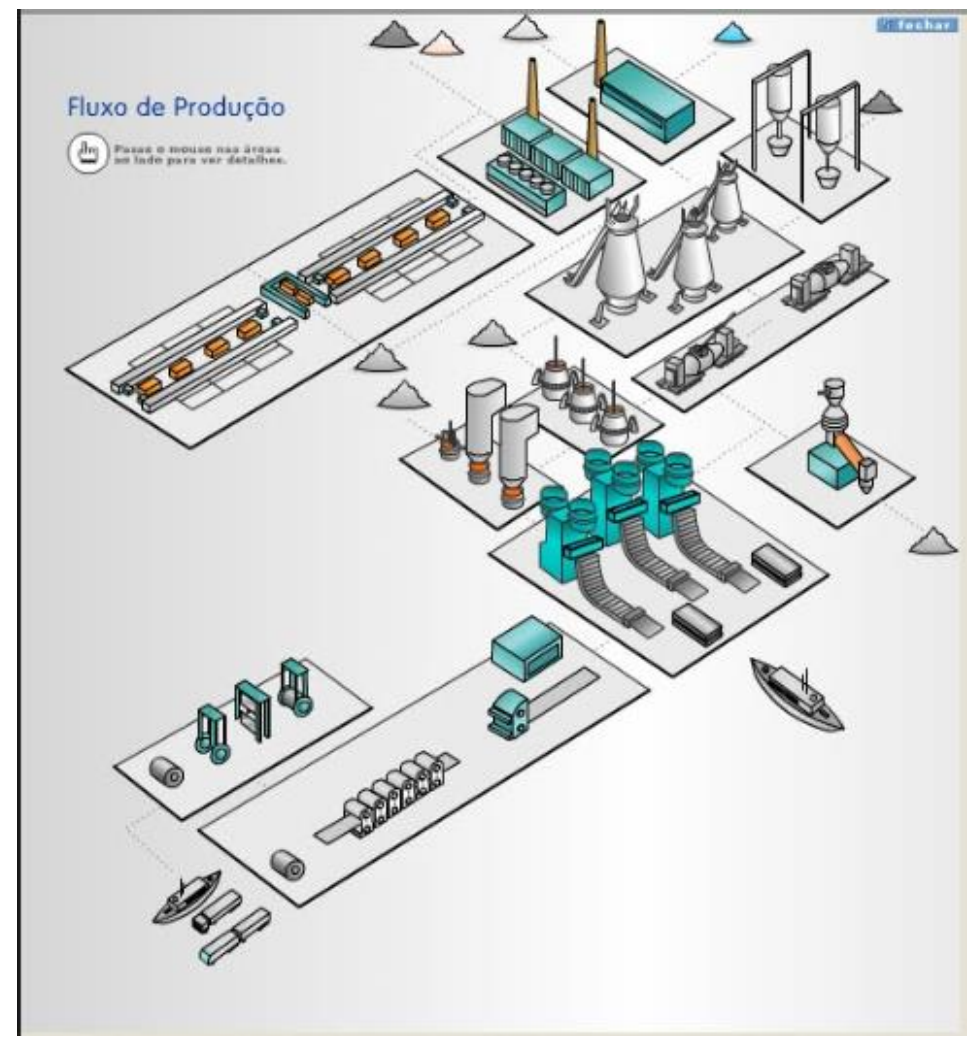

Figura I- Esquema do Fluxo de Produção da AMT 
Como histórico do processo de gestão de ativos de integridade estrutural na empresa, vemos que em meados dos anos 2000, após cerca de 17 anos de operação, começou-se a verificar problemas de maior grau e intensidade nas estruturas de suportações de equipamentos, tubulações e estruturas secundárias denominadas miscelâneas metálicas como pisos, escadas, plataformas, gerando uma preocupação do ponto de vista de segurança pessoal e operacional. Neste momento, a manutenção da companhia era focada na preventiva de componentes mecânicos e elétricos e pouco foco ainda era despendido no tratamento de anomalias de escopo de estruturas metálicas.

Em 2008, após 25 anos de operação, houve um acidente operacional com o colapso estrutural de um transportador de correia de grande relevância para o processo, onde se constatou como falha a corrosão da estrutura e dos pinos de articulação associada à carga. A partir deste momento, iniciaram-se grupos de estudo e discussões sobre a correta inspeção, planejamento e execução da manutenção destes ativos na companhia. Entretanto, outros problemas de características de integridade estrutural ocorreram em equipamentos do processo produtivo, gerando transtornos operacionais e instabilidades de produção.

Sendo assim, após diversas outras tratativas e iniciativas, associado a um benchmarking realizado em plantas do Grupo ArcelorMittal na Bélgica e Alemanha em 2015, a ArcelorMittal Tubarão introduziu um plano robusto de centralização da gestão de seus ativos de estruturas metálicas e de distribuição de fluidos gasosos cujo objetivo principal era a gestão centralizada através de metodologia de inspeção, classificação e priorização, visando a adequada alocação dos recursos do orçamento plurianual com foco na minimização dos riscos e tendo como resultado esperado o domínio técnico sobre a função manutenção de estruturas metálicas e tubulações com equipe especializada, redução de incidentes, planejamento e controle de custos de longo prazo e melhoria dos KPls associados de disponibilidade e confiabilidade.

\section{FASES DO PROCESSO}

Com o intuito de se conhecer todo o parque de ativos e a condição atual de cada ativo para a correta priorização e tratamento posterior, o projeto teve início com a fase de Inventário. Nesta fase foi definida toda a metodologia e escopo do trabalho e realizado o levantamento cadastral e de campo para mapeamento do processo.

Após isto, foi possível criar a equipe centralizada de inspeção dos ativos, bem como os planos de inspeção preventiva e preditiva e os planos para a manutenção nestes componentes com maior degradação de acordo com a matriz de priorização definida.

A Figura (II) abaixo resume as etapas do Processo e as ações constantes em cada uma delas para obtenção do objetivo e resultados esperados. 


\section{Fases do Processo}

1) Inventário:
2) Inspeção Periódica:

Realização das reinspeções sensitivas e preditivas conforme planos e padrões de inspeção e retroalimentação da planilha de cadastro geral para priorização de execução.

As fases na Inspeção Periódica constem em:

Ajuste no cadastro dos equipamentos; Balanceamento do plano de inspeção;

Elaboração dos planos e padrões;

Realização das reinspeções;

Retroalimentação do CMMS e planilha geral;

Geração dos modelos de degradação x budget plurianual ;

\section{4) Execução:}

Realização dos serviços de recuperação estrutural conforme priorização e plano plurianual definido.

As fases na etapa Execução consistem em:

Planejamento das atividades;

Programação dos recursos e paradas:

Aprovisionamento e gestão de materiais;

Fiscalização da execução;

Elaboração dos Relatórios de Execução;

Retroalimentação da Planilha de Controle Geral;
3) Planejamento e Programação:

Realização do planejamento estratégico (plurianual com base no budget disponível e risco admissível) e tático (Especificações Técnicas e Contratações).

As fases consistem em:

Elaboração do Plano Plurianual

Elaboração das Especificações Técnicas com os métodos de montagem montagem;
Contratação dos pacotes de fabricação e

Figura II - Fases do Processo de Gestão Centralizada dos Ativos de Estruturas Metálicas e Distribuição de Fluidos

\section{METODOLOGIA}

Todo o trabalho de Inventário e Inspeções periódicas posteriores foi desenvolvido tomando como base uma metodologia robusta de cunho técnico e de gerenciamento de riscos e ativos que foi compartilhada pelas plantas do Grupo ArcelorMittal e aprimorada pela equipe de Tubarão.

Tal metodologia consiste na geração de uma matriz de risco probabilidade $x$ impacto, no cadastramento de todos os ativos e a classificação dele dentro da matriz, o levantamento de seus desenhos e pesos inerentes, a definição do grau de agressividade do ambiente em que cada estrutura se encontra, a geração das curvas de degradação dos ambientes e os gráficos decisórios de orçamento plurianual para tomada de decisão. 


\subsection{MATRIZ DE RISCO - DEFINIÇÃO DE SCORES}

Para possibilitar a correta classificação e priorização de todos os ativos da planta, foi criado um procedimento com critérios de classificação claros e métricas bem definidas, de forma a se padronizar as observação e inspeções e classificá-las dentro de uma matriz de risco de probabilidade ou severidade $\mathrm{x}$ impacto.

Na metodologia proposta a denominação Score é o rating ao qual cada ativo é classificado e sua escala varia de 1 a 5 , sendo o Score 1 uma estrutura ou tubulação com severa intensidade de deterioração, gerando risco à produção ou pessoas e por conseguinte, o Score 5, uma estrutura ou tubulação com pintura íntegra, sem danos relevantes ou aparentes.

Abaixo estão figuras com um exemplo do padrão de classificação destas estruturas, que é além de descritivo, também visual e a matriz de risco x impacto associada.

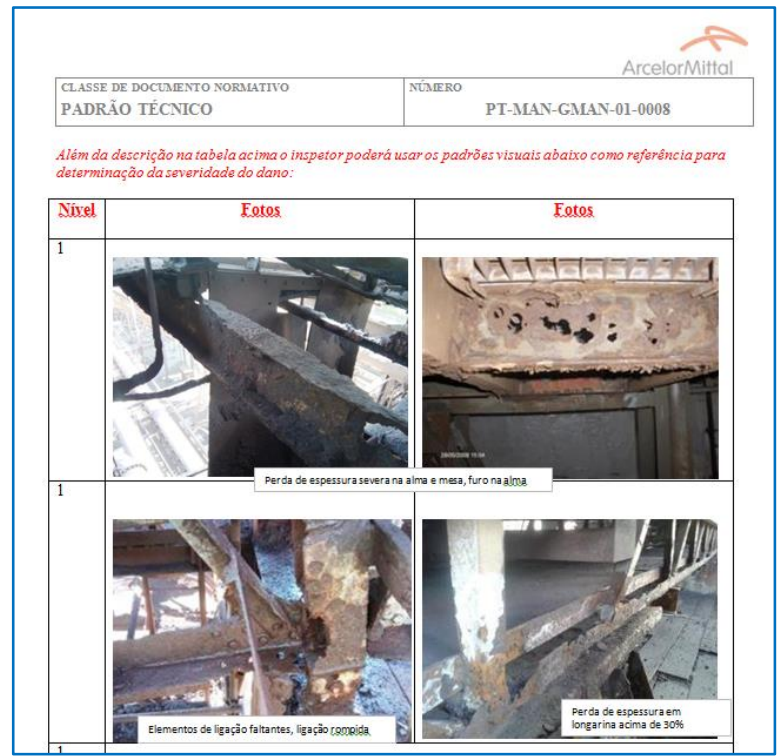

Figura III Trecho do procedimento de definição de classificação com padrão visual

\begin{tabular}{|c|c|c|c|c|c|c|c|}
\hline \multirow{3}{*}{\multicolumn{3}{|c|}{$\begin{array}{c}\text { Matriz de Prioridades } \\
\text { Escala de Severidade } x \text { Escala } \\
\text { de Impacto da Falha }\end{array}$}} & \multicolumn{5}{|c|}{ Impacto da Falha / Escala de Consequências } \\
\hline & & & \multirow{2}{*}{$\begin{array}{l}\text { Grave / } \\
\text { Global } \\
\text { A }\end{array}$} & \multirow{2}{*}{\begin{tabular}{|r|}
$\begin{array}{l}\text { Moderada / } \\
\text { Local }\end{array}$ \\
B \\
\end{tabular}} & \multirow{2}{*}{$\begin{array}{l}\text { Leve / } \\
\text { Local } \\
\\
\text { C }\end{array}$} & \multirow{2}{*}{$\begin{array}{r}\text { Despresível } \\
\text { D } \\
\end{array}$} & \multirow{2}{*}{ Sem risco } \\
\hline & & & & & & & \\
\hline \multirow{5}{*}{$\begin{array}{l}\text { Severidade } \\
\text { do Dano / } \\
\text { Probabilidade } \\
\text { da Falha }\end{array}$} & Severa & 1 & Score 1 & Score 1 & Score 2 & Score 3 & Score 3 \\
\hline & Alta & 2 & Score 2 & Score 2 & Score 2 & Score 3 & Score 3 \\
\hline & Média & 3 & Score 3 & Score 3 & Score 3 & Score 4 & Score 4 \\
\hline & Baixa & 4 & Score 4 & Score 4 & Score 4 & Score 5 & Score 5 \\
\hline & $\begin{array}{l}\text { Sem } \\
\text { danos }\end{array}$ & 5 & Score 5 & Score 5 & Score 5 & Score 5 & Score 5 \\
\hline
\end{tabular}

Figura IV- Matriz de risco de Classificação dos Scores- Probabilidade x Impacto 


\section{2 - CADASTRAMENTO DOS ATIVOS E LEVANTAMENTO DE DADOS}

Através da definição do escopo detalhado de atuação da equipe centralizada de gestão de ativos de estruturas metálicas, foi realizado o inventário de todos os ativos da planta, com o cadastramento dos itens existentes ou novos itens quando aplicável no Sistema Integrado de Manutenção e realizado o levantamento de todos os dados cadastrais destes ativos como desenhos, massa (kg, tonelada) por região, área ( $\mathrm{m}^{2}$ de pintura), área operacional, dentre outros dados.

O parque atual de estruturas metálicas da companhia objeto de escopo deste processo conta com mais de 70.000 toneladas de aço e cerca de 1200 equipamentos.

\begin{tabular}{|c|c|c|}
\hline Equipamentos Inventariados & Quant & Toneladas \\
\hline Transportadores de Correia & 353 & 14.672 \\
\hline Torres de transferência & 128 & 3.109 \\
\hline Prédios Industriais - Galpões & 129 & 23.466 \\
\hline Sistemas de despoeiramento & 48 & 3.323 \\
\hline Pipe Racks (792 racks - 108 linhas/equipamentos) & 108 & 3.176 \\
\hline Outros (silos, tanques, suportação de equip diversos) & 381 & 21.758 \\
\hline Tubulações - Distribuição Fluídos - Limite bateria Energia & $50 \mathrm{~km}$ & 4.900 \\
\hline Quantidade total de equipamentos & 1147 & 74.404 \\
\hline
\end{tabular}

TABELA I - Quadro de Equipamentos Inventariados

\subsection{LEVANTAMENTO DE CAMPO, CLASSIFICAÇÃO E GERAÇÃO DOS RELATÓRIOS}

Depois de levantado o parque de equipamentos (estruturas e tubulações), foram realizadas inspeções de campo com o objetivo de classificar a degradação destas estruturas com base no padrão e metodologia gerada. Todos os equipamentos foram inspecionados por técnica sensitiva no primeiro momento, pois o objetivo desta primeira etapa era ter uma visão holística da planta e seus graus de severidade por área, bem como os custos macros envolvidos. Esta inspeção consistia em visita aos equipamentos, visualização dos problemas, relatório fotográfico, identificação dos danos e classificação. Após inspeção, o inspetor gerava o relatório da inspeção com todos os dados pertinentes. A Figura (V) mostra um exemplo de relatório gerado. 


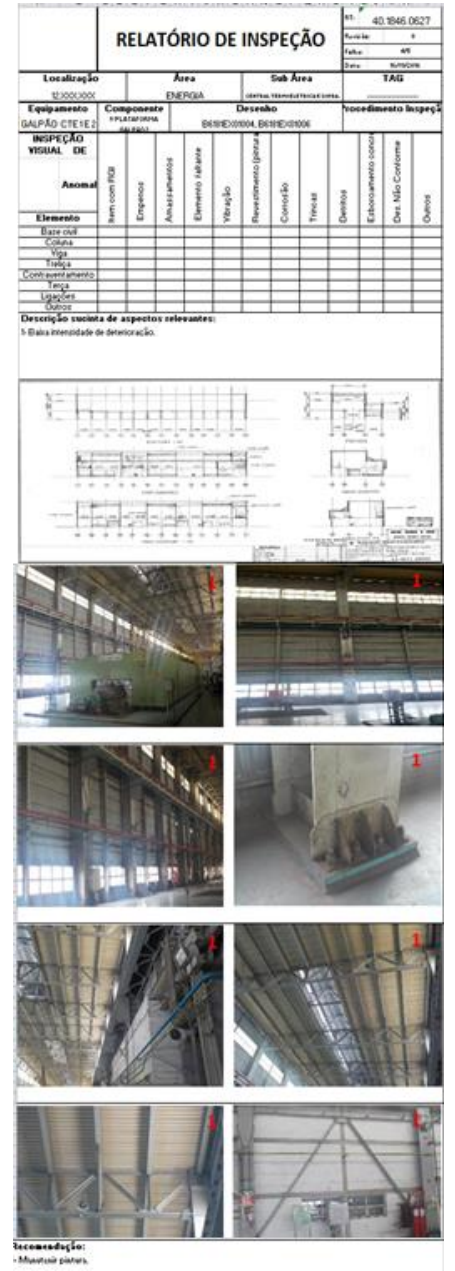

FIGURA V- Exemplo de Relatório de Inspeção Gerado

\subsection{GERAÇÃO DOS MODELOS DE DEGRADAÇÃO}

Após concluído o levantamento de campo, foi possível realizar todo tipo de análise e relatório necessário ao apoio de tomada de decisão e gestão dos ativos e manutenção de estruturas metálicas e tubulações.

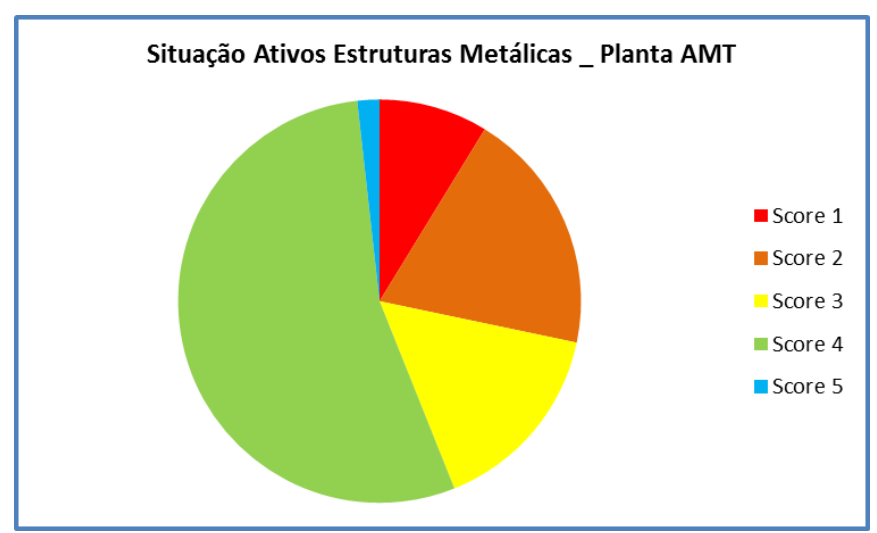

FIGURA (VI) - Exemplo de Gráficos e Dados - Classificação do Parque Industrial em Scores 
A principal ferramenta desenvolvida pela equipe de gestão centralizada foi a sistematização através da análise quantitativa e visual do risco associado ao processo atual e as decisões de investimento com manutenções e pintura destes ativos ao longo dos anos.

Isto só foi possível através da determinação prévia das curvas de degradação das estruturas ao longo do tempo. Estas curvas foram geradas tomando-se como referência a Norma ISO 12944 e estudos prévios internos da ArcelorMittal Tubarão para determinação da taxa de corrosividade de cada ambiente industrial que o ativo está inserido e qual a taxa de aceleração da degradação a que ele será exposto face a este ambiente.

A Norma ISO 12944 que estabelece a taxa de perda de espessura média de um componente metálico com base em condições ambientais. A engenharia da ArcelorMittal Tubarão já havia realizado estudos de validação/ aprimoramento destas taxas para a realidade de sua planta com a exposição de corpos de prova ao ambiente e medição destas taxas reais de perda de massa. De posse deste conhecimento, foram geradas as curvas de degradação para cada área operacional como mostrado na Figura (VII).

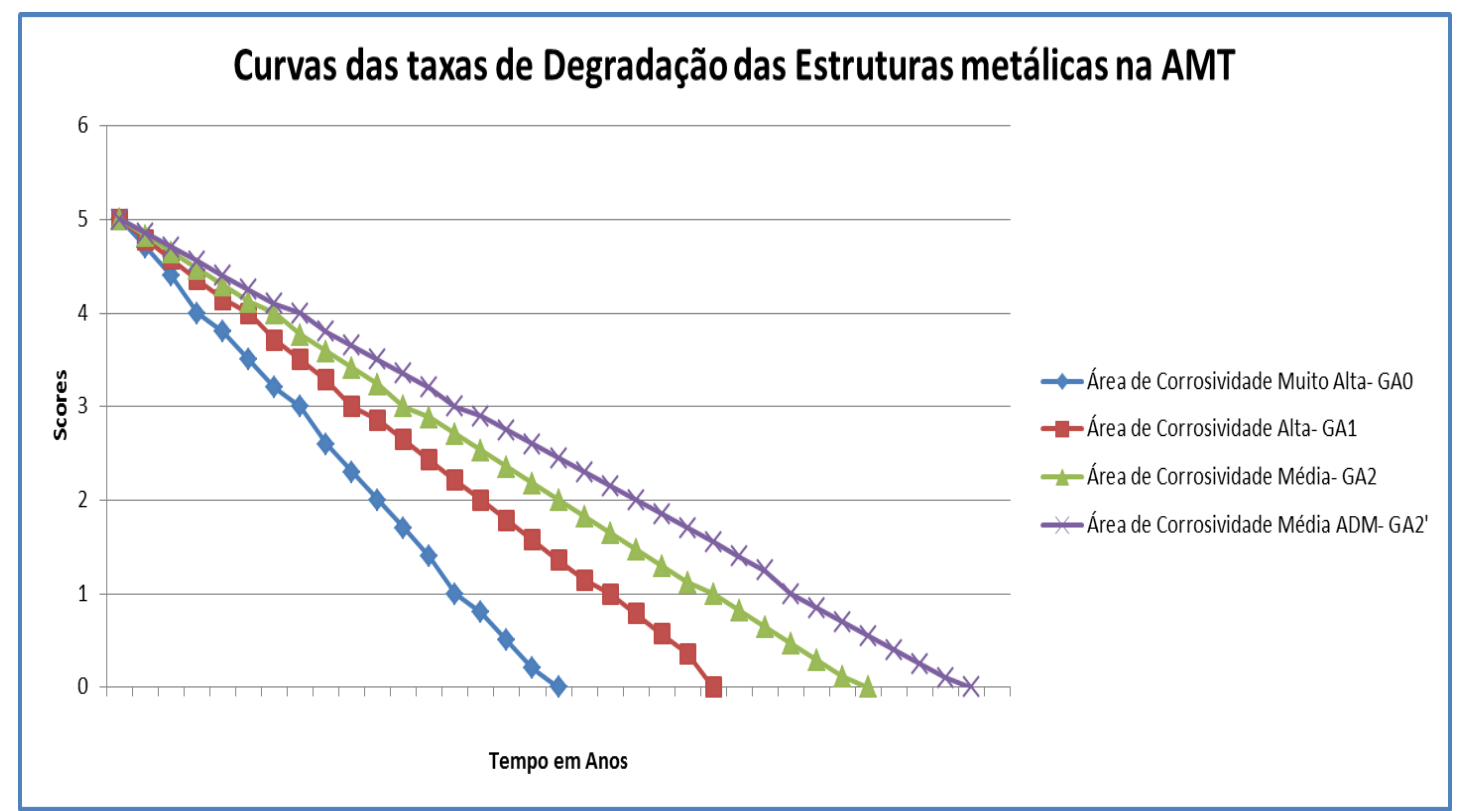

FIGURA VII- Curvas de Degradação das Estruturas Metálicas na Arcelormittal Tubarão por Área Operacional

Tendo como base o Score de cada ativo e a área que está instalado, é possível identificar a taxa de degradação de cada ativo individualmente e da planta como um todo, conhecendo-se e estabelecendo-se, portanto, cenários possíveis, viáveis ou desejáveis para cada destinação de verba aplicada. Tal ferramenta permite a gestão dos ativos com a adequada alocação dos recursos do budget com foco na minimização dos riscos. 


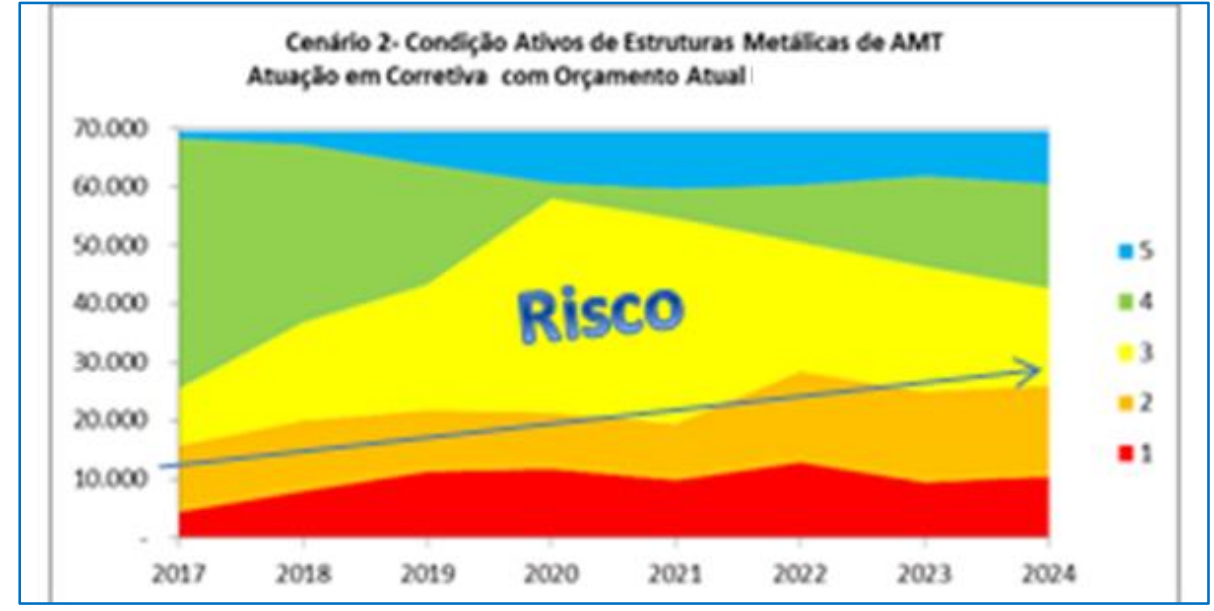

FIGURA VIII - Exemplo de Gráfico Decisório do Modelo de Degradação

8- Cenários Plano Estratégico

ANÁLISE GESTÃO DOS ATIVOS DE ESTRUTURAS METÁLICAS E RISCOS

Cenário 1

Estado Atual com evolução da degradação sem fazer nada

(sem executar nenhuma

manutenção de agora em diante)

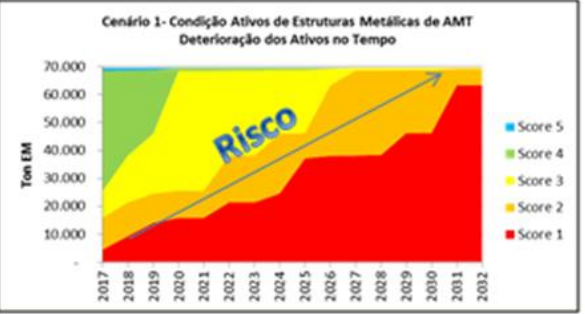

Cenário 2

Cenário baseado no Estado Atual e na tendência futura com base na manutenção dos mesmos gastos atuais

Cenário 3

Manutenção corretiva inicial

visando zero scores 1 e 2 em 5

anos e $80 \%$ Scores 4 e 5 .

considerando pintura no ponto ótimo.

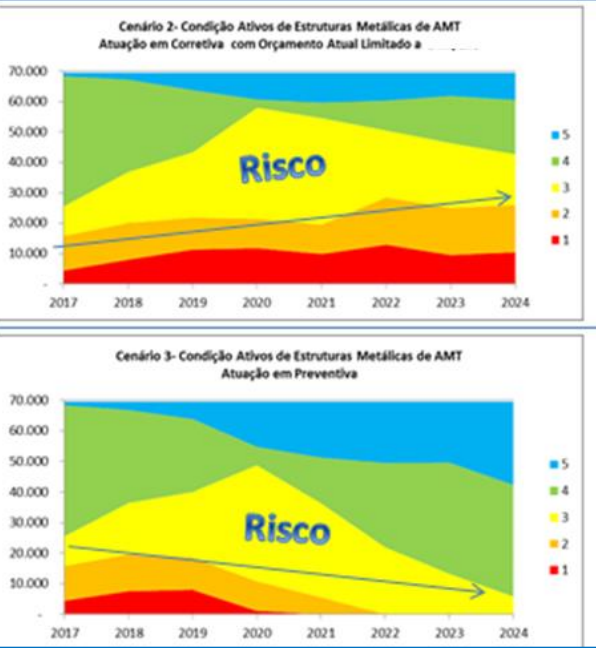

FIGURA IX - Exemplo de Avaliação de Cenários Possíveis em Planejamento Estratégico para Determinação de Custo Ótimo de Manutenção 


\section{INSPEÇÃO CENTRALIZADA, PLANEJAMENTO E EXECUÇÃO}

Após concluídas as etapas de definições metodológicas e de inventário, foi criada uma equipe centralizada de Gestão de ativos de Integridade Estrutural na Usina de forma a dar perenidade ao processo.

Esta equipe trabalha com métodos de inspeção sensitiva e preditiva no intuito de reinspecionar os ativos levantados durante o Inventário inicial, atualizando os Scores de cada equipamento e as ações de manutenção necessárias à retirada da condição de risco.

Uma das vantagens da equipe especializada e centralizada é a grande especialização do time de campo de inspeção, com foco na qualidade e técnicas modernas como utilização de máquinas fotográficas de alta definição e longo alcance, utilização de drones para inspeção e técnicas preditivas como ultrassom e medição de espessura.

Para criação do plano de inspeção de modo a se obter o correto balanceamento deste plano para uma maior produtividade dos inspetores e assertividade na estabilidade do processo, foram utilizados como critérios os scores atuais das estruturas, a área em que o ativo está inserido, sua localização física e proximidades e a quantidade de equipamentos total definindo-se, portanto, a frequência de inspeção necessária para cada equipamento.

Como resultado das inspeções, os inspetores geram demandas através de Ordens de serviços para execução das manutenções e reforços estruturais. A visão sistêmica e centralizada dos ativos permite a priorização e alocação da verba do orçamento anual nos pontos de maior interesse com base em toda metodologia gerada e definida, dando confiabilidade e transparência ao processo de gestão.

\section{5 - CONCLUSÃO}

A gestão da manutenção dos ativos de estruturas metálicas e tubulações em uma indústria é sem dúvida um grande desafio dos profissionais da área até mesmo pela sua característica de evolução no longo prazo, e é, em grande parte, preterida, frente às manutenções eletromecânicas de uma planta. De tal forma que é preciso uma visão estratégica com aplicação de metodologia sólida de visão mais preventiva e menos reativa em relação ao tema para garantir a estabilidade dos processos e correta gestão destes ativos para a perenidade da empresa.

A metodologia de gestão de ativos de integridade estrutural e distribuição de fluídos desenvolvida e aprimorada pela ArcelorMittal Tubarão permite a antecipação de problemas que podem afetar a estabilidade operacional, a atuação da manutenção de forma preventiva e otimizada com redução de custos no longo prazo e a preservação destes ativos. 